\title{
Modeling Heat Pump Recharge of a Personal Conditioning System with Latent Heat Storage
}

\author{
Rohit Dhumane Jiazhen Ling Vikrant Aute Reinhard Radermacher \\ Center for Environmental Energy Engineering, Department of Mechanical Engineering, University of Maryland, College \\ Park, MD, USA 20742 \\ dhumane@terpmail.umd.edu; \{jiazhen, vikrant, raderm\}@umd.edu
}

\begin{abstract}
Roving Comforter provides personal cooling in the range of $150 \mathrm{~W}$ using vapor compression cycle (VCC) up to 4 hours. During this operation, the condenser heat is stored in a latent heat storage made of phase change material (PCM). This heat needs to be discharged before next cooling operation. A heat pump mode is considered and analyzed for this heat discharge in the present article. The cycle is modeled using CEEEModelicalibrary, which is a commercial package for complex vapor compression systems. Equations and assumptions involved in modeling some of the components is presented. Programming and modeling decisions for PCM modeling are discussed in detail. A parametric study is conducted with the heat pump system model to identify merits and demerits of operating heat pump cycle at various compressor RPM's.
\end{abstract}

Keywords: Heat Pump, PCM, Latent Storage, Personal Comfort

\section{Introduction}

World Wildlife Fund recently reported "We are the first generation to know we are destroying our planet and the last one that can do anything about it." The lifestyle choices in the modern world are not sustainable and need a thorough scrutiny.

Space heating and cooling takes up significant portion of worldwide primary energy consumption. The current practice of maintaining conditioned space temperature within a narrow temperature range on the one hand, does consume a huge amount of energy to condition the total space in the building, including the unoccupied space; on the other hand, cannot always guarantee the comfort of $80 \%$ occupants due to the individual preference (Zhang, Arens and Zhai, 2015). The temperature range for comfort were developed based on predictive mean vote or adaptive models and is not ideal for individual comfort (Kim, Schiavon and Brager, 2018). Personal conditioning system allow building temperature set-points to be elevated without compromising thermal comfort. Space heating and cooling energy consumption can be reduced to the order of $10 \%$ per ${ }^{\circ} \mathrm{C}$ elevation in temperature set-points of buildings (Hoyt, Arens and Zhang, 2015).

Portable personal comfort systems have potential to provide improved thermal comfort, reduced energy consumption and ways to mitigate demerits of existing personal comfort systems (Dhumane et al., 2017). Roving Comforter (RoCo) is being developed to provide better individual thermal comfort at much lesser energy consumption. The first prototype (Dhumane et al., 2019) used paraffin based phase change material for latent heat storage. For recharge operation, a thermosiphon operation was used (Dhumane et al., 2018). The technology can provide annual energy savings per person up to $\$ 130$ (Heidarinejad et al., 2018).

The current prototype (see Figure 1) provides 4 hours of cooling, but requires slightly more than 6 hours to discharge heat from the PCM storage by thermosiphon operation. A heat pump operation can provide faster recharge than thermosiphon, but consume significantly higher power. It is necessary to model this operation to understand it quantitatively and also identify ideal operating parameters. Modeling this heat pump operation is the objective of the present article.

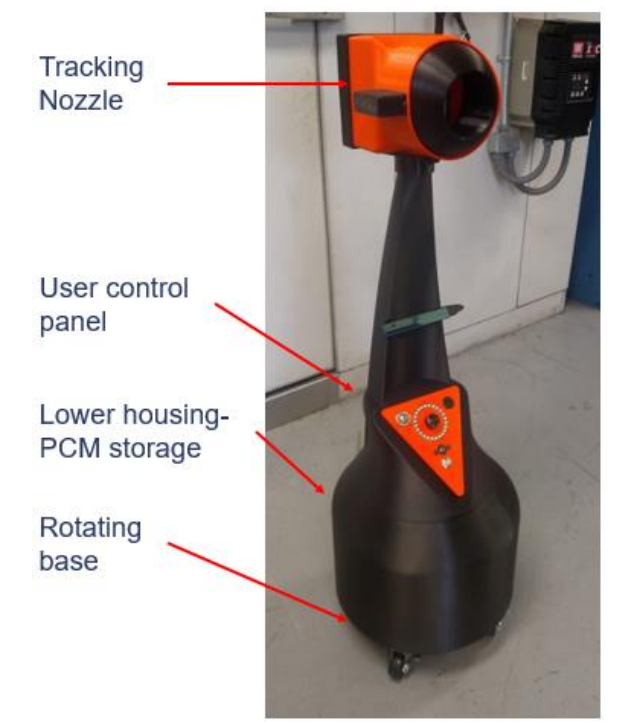

Figure 1. Current Prototype of Roving Comforter. 


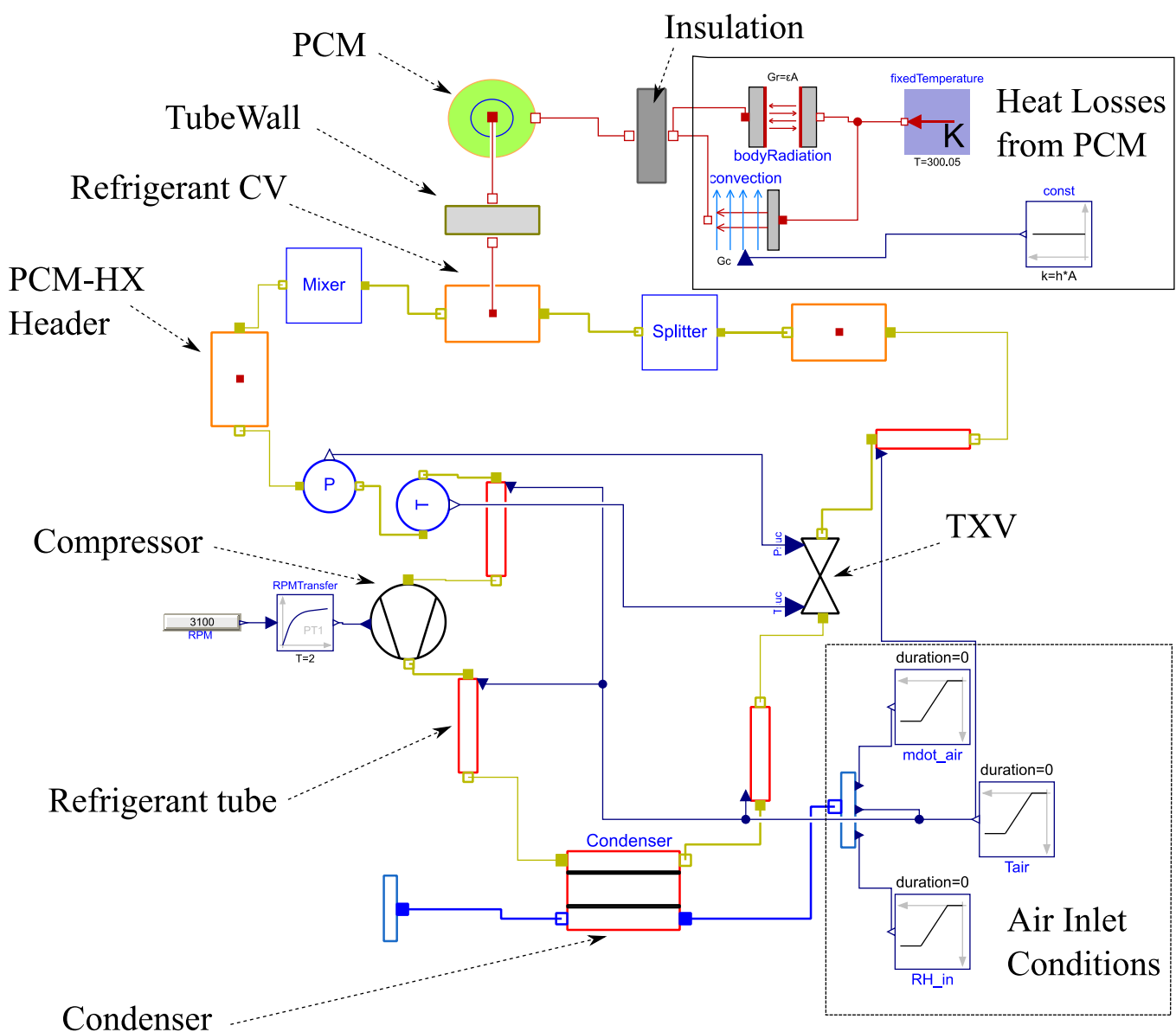

Figure 2. Model diagram for heat pump recharge

\section{HEAT PUMP RECHARGE}

The schematic of the heat pump operation of RoCo is shown in Figure 3. The schematic for cooling mode is shown in Figure 4. The grey portion of the refrigerant circuit does not have any refrigerant flow. A reversible four-way valve is used to control the refrigerant flow direction and switch the operating conditions between cooling and PCM recharging (solidification). To be more specific, the four-way valve directs the discharge refrigerant from the compressor to the PCM HX in the cooling while directs the discharged refrigerant to the air-to-refrigerant Condenser (as shown in the figure) in the PCM recharging. The compressor used in RoCo is of the variable-speed type and the recharge time may be controlled by adjusting its RPM. The recharge time can be reduced with higher RPM but the power consumption is, as a result of higher RPM, increased. There are two TXVs in the circuit for heat pump, each protected by a check valve which ensures only one TXV operates in each mode. The bulbs of the TXV are connected to outlet of either the air to refrigerant heat exchanger or the PCM-HX. During the cooling operation, the outlet of air to refrigerant heat exchanger (marked as condenser in Figure 3 ) is connected to the bulb of TXV, while the outlet of PCM-HX is connected to the bulb of the second TXV. This second TXV is operational during the heat pump operation.

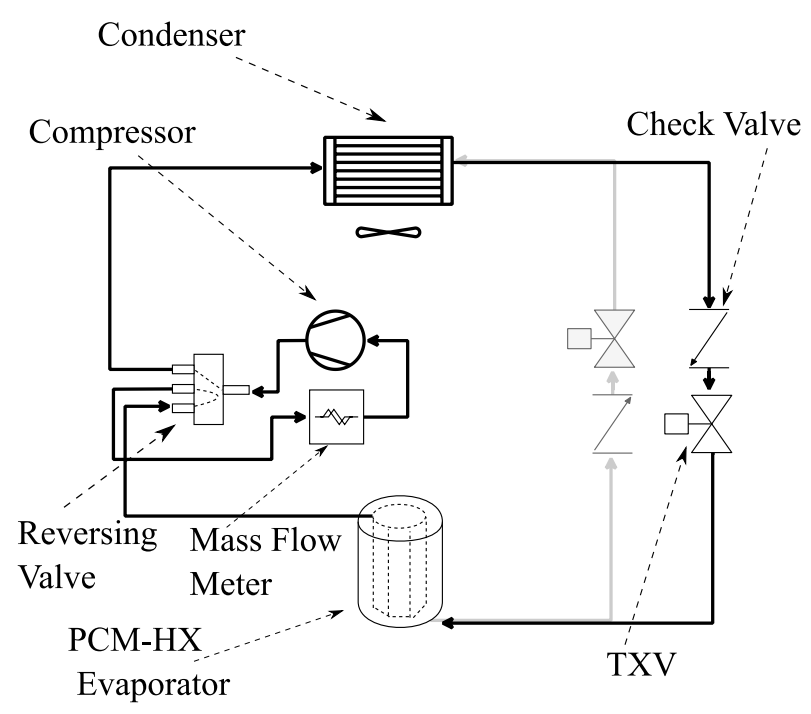

Figure 3. Schematic of Heat Pump Operation. 


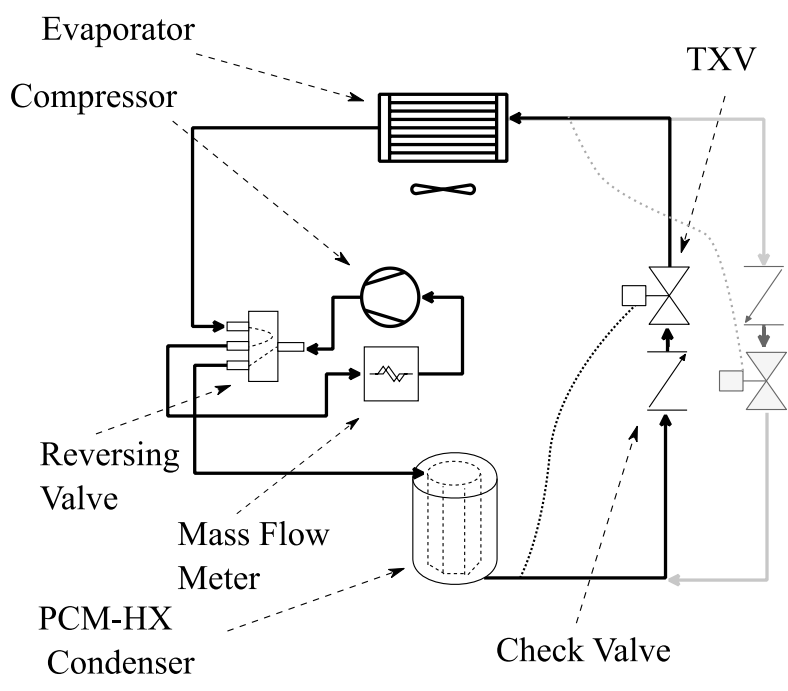

Figure 4. Schematic of Cooling Operation.

\section{MODEL DEVELOPMENT}

The model diagram for the heat pump model is shown in Figure 2. The component models are obtained from CEEEModelicaLibrary (CML), which has been discussed in detail in Qiao (2014). The components used in the present investigation have been updated to stream connectors (Franke et al., 2009). The modifications for heat transfer coefficient and pressure drop characteristics as suggested by Dermont et al. (2016) have been incorporated. The PCM model is developed for the present investigation and is discussed in detail. Other components are described briefly and important input parameters for each of them are presented in this section.

\subsection{Phase Change Material Storage}

The PCM storage used for the prototype involves graphite enhancement to paraffin based PureTemp 37. The bulk density of the material is $183 \mathrm{~kg} / \mathrm{m}^{3}$. The PCM storage is cylindrical with diameter $=0.254 \mathrm{~m}$ and height $=0.305 \mathrm{~m}$. Eight $0.0063 \mathrm{~m}$ copper tubes are inserted at a distance of $0.051 \mathrm{~m}$ from the outer diameter, with headers connecting at bottom and the top. The symmetric location of the refrigerant tubes is exploited to allow simplification in modeling.

The cross-section of the PCM storage is shown below in Figure 5. The graphite foam prevents circulation of liquid PCM during phase change and the control volume can be modeled as a pure conduction problem. Radial mode of heat transfer is assumed to be dominant to avoid discretization along the height of the PCM cylinder. The symmetric location of the refrigerant tubes allows further simplification in modeling. Only a single tube is modeled and the behavior of the entire thermal storage is captured by scaling the behavior of this single section by eight. This is done using the Splitter and Mixer components from CML. The PCM surrounding each refrigerant tube is in the shape of a $1 / 8$ pie. However, the control volume is assumed to be cylindrical to allow modeling as a 1-D conduction problem. This assumption is shown in Figure 5.

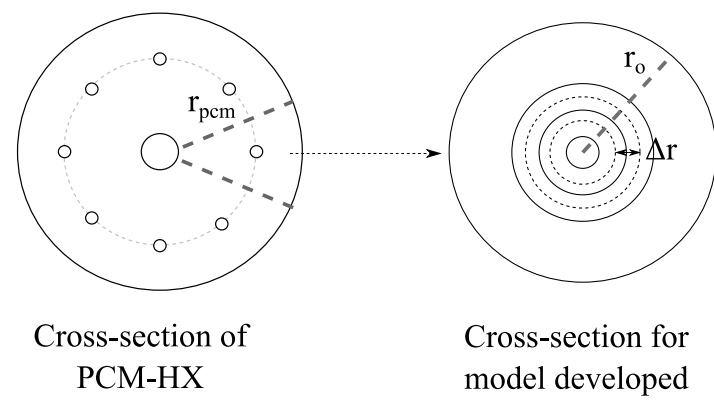

Figure 5. Cross section for modeling PCM.

The energy equation for 1-D cylindrical conduction with the assumptions mentioned above is shown in Equation 1. Here $\rho$ is the average of the density of PCM in solid and liquid phases. The difference between these two values is less than $10 \%$ and this assumption allows treatment of density as a constant for the differential equation. Similarly, the thermal conductivity $(\mathrm{k})$ is also treated constant for both phases. The difference is negligible in reality since the majority of heat transfer in graphite enhanced PCM is via graphite.

$$
\rho \frac{\partial h}{\partial t}=\frac{1}{r} \frac{\partial}{\partial r}\left(k r \frac{\partial T}{\partial r}\right)
$$

The specific enthalpy (h) of the PCM is estimated using temperature transforming model of $\mathrm{Cao}$ and Faghri (1991). As shown in Equation 2, the specific enthalpy is written as a function of specific heat capacity (c), a source term (s) and temperature difference from the melting point $\left(\mathrm{T}_{\mathrm{m}}\right)$. The paraffin based PCM typically melts over a temperature range and this allows values of specific heat capacity in two-phase region to be defined (not equal to infinity as in the case of pure materials like water). Temperature $\left(\mathrm{T}_{\mathrm{m}}\right)$ is the mid-point of this temperature glide during phase change. The specific heat capacity and source terms are calculated using Equations 3 and 4.

$$
\begin{gathered}
h=c\left(T-T_{m}\right)+s \\
c=\left\{\begin{array}{lcc}
c_{s} & \mathrm{~T}^{-} \mathrm{T}_{m}<-\delta \mathrm{T} & \text { (solid) } \\
\frac{c_{s}+c_{l}}{2}+\frac{H}{2 \delta T} & -\delta \mathrm{T} \leq \mathrm{T}^{-} \mathrm{T}_{m} \leq \delta \mathrm{T} & \text { (two-phase) } \\
c_{l} & \mathrm{~T}-\mathrm{T}_{m}>\delta \mathrm{T} & \text { (liquid) }
\end{array}\right. \\
s=\left\{\begin{array}{lcc}
c_{s} \delta \mathrm{T} & \mathrm{T}_{m}<-\delta \mathrm{T} & \text { (solid) } \\
\left(\frac{c_{s}+c_{l}}{2}\right) \delta \mathrm{T}+\frac{H}{2} & -\delta \mathrm{T} \leq \mathrm{T}-\mathrm{T}_{m} \leq \delta \mathrm{T} & \text { (two-phase) } \\
c_{s} \delta \mathrm{T}+H & \mathrm{~T}^{-} \mathrm{T}_{m}>\delta \mathrm{T} & \text { (liquid) }
\end{array}\right.
\end{gathered}
$$

In these equations, $\mathrm{H}$ is the latent heat capacity of the PCM, $\delta \mathrm{T}$ is the temperature glide and $\mathrm{c}_{\mathrm{s}}$ and $\mathrm{c}_{1}$ are solid phase and liquid phase specific heat capacity values.

Finite volume method is used to model the cylindrical control volume of the PCM. A staggered grid is adopted 
with the mass and energy of the PCM assumed to be concentrated at the center, while the heat fluxes calculated the boundary. The number of discretization for the control volume is 5 .

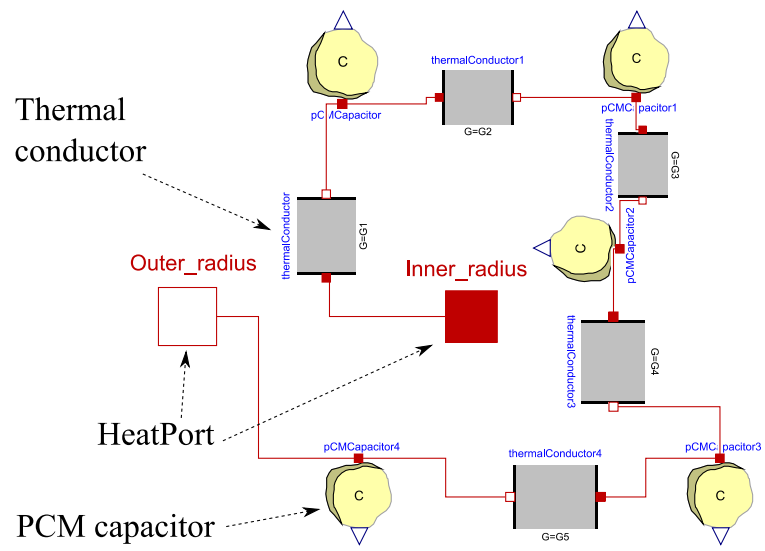

Figure 6. Model diagram for discretized PCM control volume.

The staggered grid is implemented using an alternating network of Modelica.Thermal. HeatTransfer. Components. Thermalconductor and PCMConductor. The arrangement is shown in Figure 6. Each of these components may also be created as vector arrays and connected using for loops for generality. The connections between these components are made using HeatPort connector.

\subsubsection{Heat Transfer}

The ThermalConductor requires an input of thermal conductance $(\mathrm{G})$. For the first control volume (closest to the refrigerant tube in the center of cylinder), it can be calculated using Equation 5.

$$
G_{1}=\frac{k\left(2 \pi\left(\frac{r_{1}+r_{1.5}}{2}\right) L\right)}{\Delta r / 2}
$$

The index $i=1$, for the refrigerant tube outer diameter and for discretization of 5, the outer diameter of PCM cylinder control volume gets $i=6$. The solid lines at the border of control volume get integer indices 2,3,4 and 5, while the dotted lines at center have index of 1.5, 2.5 .... 5.5. The thermal conductance between the refrigerant tube and first control volume is evaluated by Equation 6.

$$
G_{i}=\frac{k\left(2 \pi r_{i} L\right)}{\Delta r} \quad i=2,3,4,5
$$

\subsubsection{Heat Storage}

The PCMConductor is a lumped control volume for heat storage. It is analogous to Modelica.Thermal. HeatTransfer.Components. HeatCapacitor but for PCM application. Equations 1 to 4 are written in this component. The melt fraction $(\lambda)$ is calculated using Equation 7.

$$
\lambda=\max \left(0, \min \left(1, \frac{h}{H}\right)\right)
$$

The portion of the code performing this task is shown below.

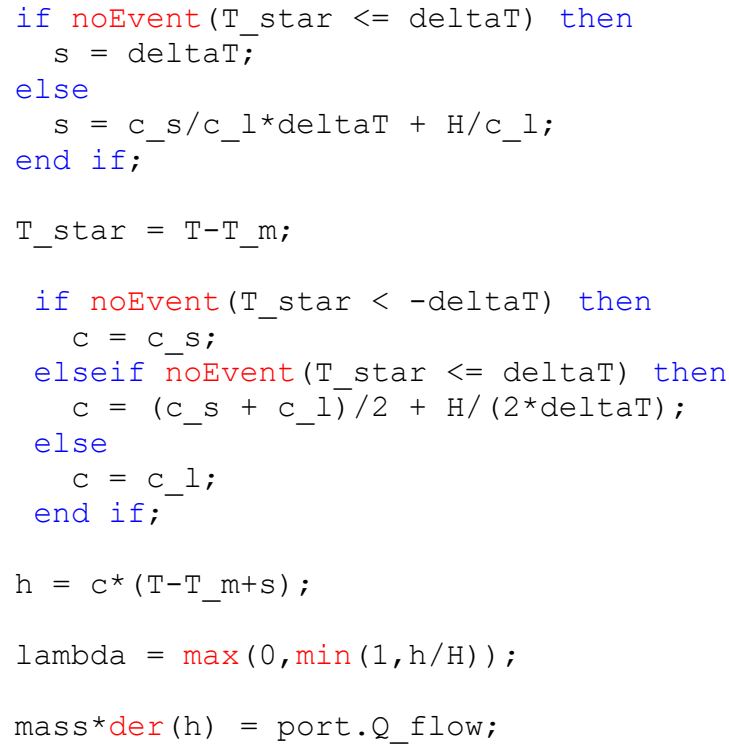

\subsubsection{Heat Losses}

To model heat losses from PCM to the surroundings a PCM container is modeled. The container is modeled using a component similar to Modelica.Fluid.Examples.HeatExchanger.Bas eclasses.WallconstProps. The heat storage is calculated using mass for the $1 / 8^{\text {th }}$ pie. Thermal resistance for each of the pie is in parallel to each other. In this case, the total thermal resistance for each of the pie will be 8 times the thermal resistance of the entire cylindrical container.

Heat losses by both natural convection and radiation are calculated using Modelica.Thermal. HeatTransfer. Components. Convection and Modelica.Thermal. HeatTransfer. Components. BodyRadiation. The airside heat transfer coefficient for natural convection is calculated assuming the cylinder outer surface is a flat vertical plate where Churchill and Chu (1975) correlation is applicable. The heat transfer coefficient is calculated separately using average values of fluid properties and a fixed value is provided.

\subsection{Splitter and Mixer}

These components are useful for modeling symmetric circuits. The splitter component splits the refrigerant entering into equal portions, while the mixer merges it back to the complete value. Heat transfer is calculated at only one of the symmetric portions and then scaled back 
to the total number of symmetric portions. The component is assumed to be both isenthalpic as well as isobaric. The implementation of this component is shown below. The connections are made using FlowPort connector from Modelica Standard Library, with port A for inlet and port B for outlet.

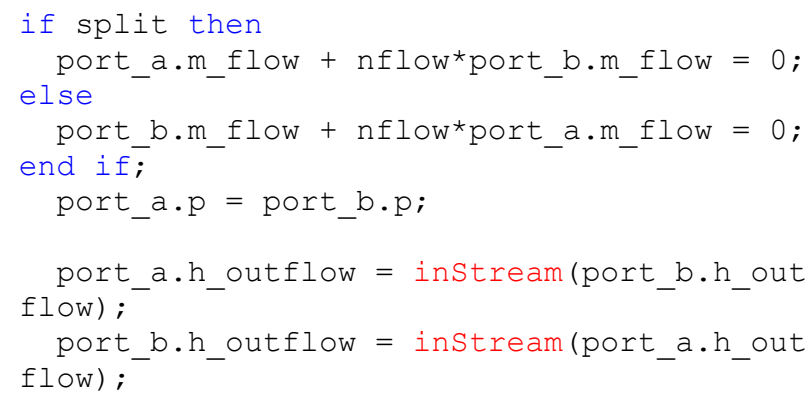

\subsection{Thermal Expansion Valve}

The thermostatic expansion valve (TXV) is comprised of two sections: the throttling section, which regulates the refrigerant mass flow through the valve, and the sensor bulb section, which monitors the refrigerant temperature leaving the evaporator and converts the change in temperature into the change in pressure on the diaphragm, causing the needle to move upward or downward. Since the superheat is sensed by the bulb attached on the suction line, there is a delay between the sensed superheat and the actual superheat. This delay occurs due to the thermal inertia of the bulb and the heat transfer resistance between the substance in the bulb and the refrigerant flowing in the suction line. The sensor bulb is modeled as a lumped section in the present analysis, and its temperature variation with time is given by

$$
m_{b} c_{p, b} \frac{d T_{b}}{d t}=\frac{T_{a m b}-T_{b}}{R_{a b}}+\frac{T_{w}-T_{b}}{R_{w b}}
$$

where $M_{b}$ is the mass of the sensor bulb, $c_{p, b}$ is the specific heat, $T_{b}$ is the temperature of the bulb, $T_{w}$ is the temperature of the tube wall to which the sensor bulb is attached, $R_{a b}$ is the thermal resistance between the ambient and the bulb, and $R_{w b}$ is the thermal contact resistance between the tube wall and bulb. Further details of the TXV model can be found in Qiao et al. (2012)

\subsection{Compressor}

The compressor is often treated as a quasi-steady-state component in transient simulations because the time scales associated with the variation of the compressor mass flow rate are very small compared to those associated with heat exchanger. The compressor is modeled by using three efficiencies: isentropic efficiency $\left(\eta_{i s e}\right)$, volumetric efficiency $\left(\eta_{v o l}\right)$, and motor efficiency $\left(\eta_{\text {motor }}\right)$. Equations 9-11 describe the model.

$$
\begin{gathered}
h_{\text {out }}=h_{\text {in }}+\frac{h_{\text {out }, s}-h_{\text {in }}}{\eta_{\text {ise }}} \\
\dot{m}=\eta_{\text {vol }} \rho_{\text {in }} V_{d} \frac{R P M}{60} \\
\frac{\dot{m}\left(h_{\text {out }}-h_{\text {in }}\right)}{\eta_{\text {motor }}}=\dot{W}
\end{gathered}
$$

Here $\rho_{\text {in }}$ is the density of entering refrigerant vapor, $V_{d}$ is the displacement volume, $\dot{W}$ is the total work done by the compressor, $h_{\text {out }}$ is the refrigerant outlet enthalpy, $h_{i n}$ is the refrigerant inlet enthalpy, and $h_{\text {out,s }}$ is the refrigerant outlet enthalpy for isentropic compression.

\subsection{Condenser}

The condenser is a fin and tube air cooled heat exchanger component, and is modeled using a segmentby-segment heat exchanger model (See Figure 7). Details of this component are presented in Qiao (2014) and only the assumptions and capabilities are discussed here.

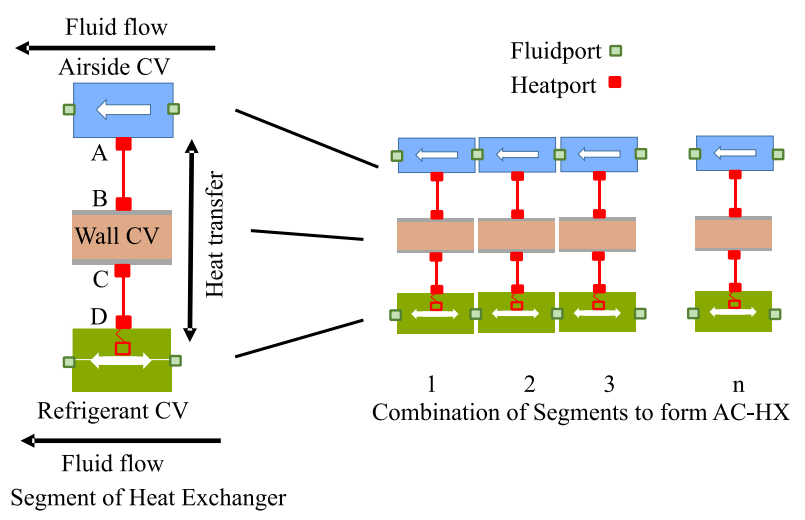

Figure 7. Schematic for Air Cooled Heat Exchanger.

The model consists of three control volumes: the refrigerant (green), finned walls (orange), and air stream (blue). Each of these is linked via HeatPorts and FluidPorts, from the Modelica Standard Library.

Tube walls and associated fins are modeled using a lumped capacitance method. In general, there is a temperature distribution on the fins. By applying the fin efficiency, however, one can lump the tube walls and fins together using one temperature. The axial conduction along the tube is neglected. $T_{\text {tube }}$ is the temperature at a node halfway along the thickness $(\Delta \mathrm{d})$ of the refrigerant tube. Energy balance for this control volume leads to Equation 12. 


$$
\left(m_{\text {tube }} c_{\text {tube }}+m_{\text {fin }} c_{\text {fin }}\right) \frac{d T_{\text {tube }}}{d t}=\dot{Q}_{r}+\dot{Q}_{a}
$$

The locations of HeatPorts A, B, C, and D are shown in Figure 7. HeatPorts $\mathrm{B}$ and $\mathrm{C}$ are used to evaluate the heat transfer within the refrigerant tubing control volume, while HeatPorts A and D are used for the airside control volume and refrigerant control volume, respectively. The thickness of the refrigerant tube is much smaller than its diameter, enabling evaluation of wall conduction by Equations 13 and 14 for the airside $\left(\mathrm{Q}_{\mathrm{a}}\right)$ and the refrigerant side $\left(\mathrm{Q}_{\mathrm{r}}\right)$.

$$
\begin{aligned}
& \dot{Q}_{r}=\frac{k A}{(\Delta d / 2)}\left(T_{C}-T_{\text {tube }}\right) \\
& \dot{Q}_{a}=\frac{k A}{(\Delta d / 2)}\left(T_{\text {tube }}-T_{B}\right)
\end{aligned}
$$

The airside and refrigerant side cooling capacities are evaluated in their respective control volumes. The outlet state of the air temperature is evaluated using $\varepsilon$-NTU approach. The refrigerant side contains transient conservation equations, which are evaluated with pressure and enthalpy as state variables. Homogenous void fraction model is used for the current investigation. However, slip-flow based void fraction models are also available for analysis involving refrigerant charge.

\section{RESULTS AND DISCUSSION}

The compressor used for RoCo is of variable speed type. Increasing the compressor speed will lead to faster recharge but increased power consumption. Parametric study is conducted on compressor RPM of 2100, 2600, 3100 and 3600 for the system operation.

All the properties of PCM required for the model are not available experimentally. As a result, properties of a PCM with similar graphite concentration from an earlier study (Dhumane et al., 2018) is used. These properties are given in Table 1.

Table 1. Properties of PCM used for modeling.

\begin{tabular}{|l|l|}
\hline Parameter & Value \\
\hline Bulk Density $\left[\mathrm{kg} \mathrm{m}^{-3}\right]$ & 143 \\
\hline Volume Fraction $[\%]$ & 6.3 \\
\hline Solid Density $\left[\mathrm{kg} \mathrm{m}^{-3}\right]$ & 1005 \\
\hline Liquid Density $\left[\mathrm{kg} \mathrm{m}^{-3}\right]$ & 930 \\
\hline Specific Heat Capacity (Solid) $\left[\mathrm{J} \mathrm{kg}^{-1} \mathrm{~K}^{-1}\right]$ & 1997 \\
\hline Specific Heat Capacity (Liquid) $\left[\mathrm{J} \mathrm{kg}^{-1} \mathrm{~K}^{-1}\right]$ & 2335 \\
\hline Latent Heat $\left[\mathrm{kJ} \mathrm{kg}^{-1}\right]$ & 178 \\
\hline Thermal Conductivity $\left[\mathrm{W} \mathrm{m}^{-1} \mathrm{~K}^{-1}\right]$ & 20.2 \\
\hline
\end{tabular}

The refrigerant used for the current system is R134a. The values of compressor efficiency are taken from the validated study of cooling mode (Dhumane et al., 2019). Nominal values are provided for calculating heat transfer and pressure drop in heat exchangers. These values are calculated using correlations available from literature. Summary of the correlations used for different phenomena is given in Table 2 .

Table 2. Correlation Summary.

\begin{tabular}{|l|l|l|}
\hline Phenomena & Heat Transfer & Pressure Drop \\
\hline $\begin{array}{l}\text { Refrigerant } \\
\text { boiling }\end{array}$ & (Shah, 1982) & $\begin{array}{l}\text { (Müller- } \\
\text { Steinhagen } \\
\text { and Heck, } \\
1986)\end{array}$ \\
\hline $\begin{array}{l}\text { Refrigerant } \\
\text { condensation }\end{array}$ & $\begin{array}{l}\text { (Müller- } \\
\text { Steinhagen } \\
\text { and Heck, } \\
\text { (Shah, 2016) }\end{array}$ \\
\hline $\begin{array}{l}\text { Refrigerant single } \\
\text { phase }\end{array}$ & $\begin{array}{l}\text { (Dittus and } \\
\text { Boelter, 1985) }\end{array}$ & $\begin{array}{l}\text { (Blasius, } \\
1913)\end{array}$ \\
\hline $\begin{array}{l}\text { Condenser airside } \\
\text { (Wang and } \\
\text { Chi, 2000) }\end{array}$ & Neglected \\
\hline $\begin{array}{l}\text { Refrigerant tube } \\
\text { heat losses to } \\
\text { ambient by natural } \\
\text { convection }\end{array}$ & $\begin{array}{l}\text { (Churchill } \\
\text { and Chu, } \\
\text { 1975) }\end{array}$ & Neglected \\
\hline
\end{tabular}

The model is simulated using Dymola 2018 with Radau-IIa solver, tolerance of 1e-6. Equidistant time steps option is unchecked from solver settings. The computer used has Intel Xeon Processor with $3.5 \mathrm{GHz}$ speed, 16 GB RAM, 64-bit Windows Operating System and x64 based Processor. The simulation speed for the system with 3100 RPM is 17.2 seconds. Runtime of other cases is comparable.

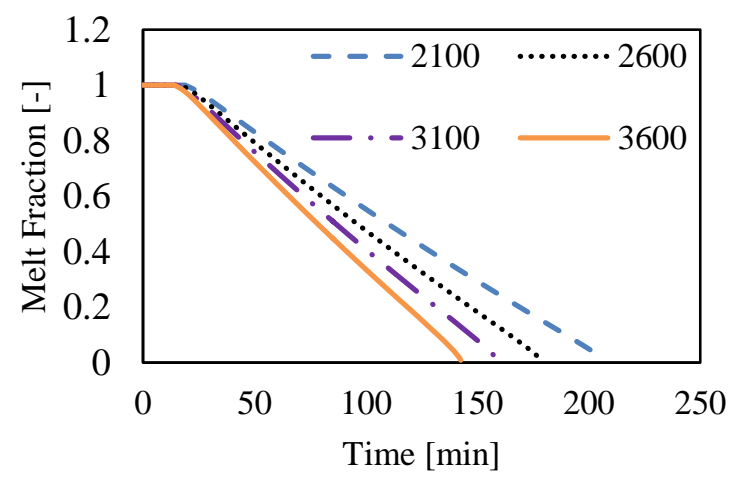

Figure 8. Rate of Solidification at different RPM.

The melt fraction heat pump operation at four different compressor RPM is shown in Figure 8, while the power consumption from compressor is shown in Figure 9. It can be observed that higher RPM leads to faster recharge, but the power consumption by the compressor to deliver the high RPM is large. Higher compressor speed leads to larger refrigerant mass flow rate and larger rate of heat release from the condenser 
during the heat pump operation. Since the time duration of recharge is different, it is necessary to compare integrated power consumption during the recharge time duration.

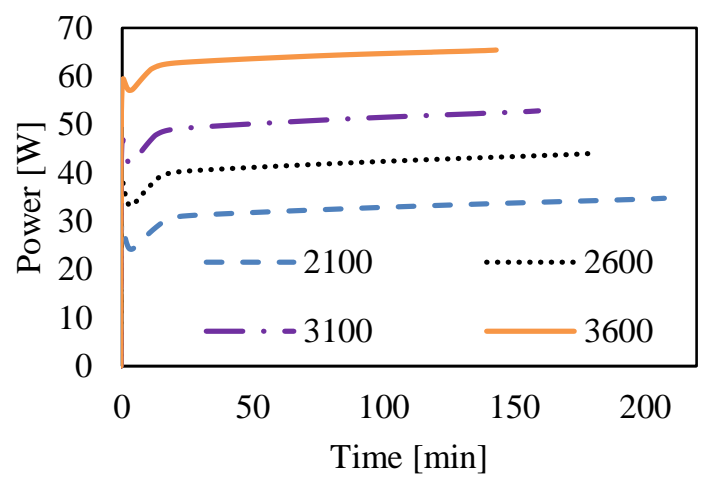

Figure 9. Compressor Power Consumption at different RPM.

A fan is also operational during the entire recharge cycle and so a 7-W power usage needs to be added to the power consumed by the compressor. This is shown in Figure 10, with a quadratic fitting trend line. The total recharge time for different heat pump cycles is plotted in Figure 11. A quadratic trend line is drawn to interpolate recharge time for RPM between simulated cases.

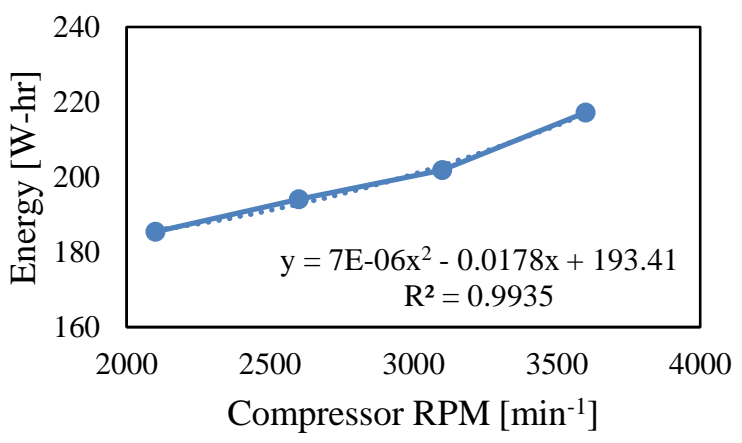

Figure 10. Integrated power consumption by heat pump operation at different compressor RPM.

From experiment data (Qiao et al., 2018), the COP for just the cooling operation is obtained to be 4.25 , with 754.0 Wh of cooling delivered at energy consumption of $177.4 \mathrm{Wh}$. For a complete cycle COP, the energy consumption of recharge cycle also needs to be added to the energy consumption during cooling operation. This is done using Equation 15, where the numerator is the total cooling capacity during cooling operation and denominator is the sum of power consumption in cooling operation and heat pump operation. Subscript ' $c$ ' stands for cooling operation, ' $r$ ' for heat pump operation.

$$
C O P_{c y c}=\frac{\int_{0}^{t_{c}} \dot{Q}_{c} d t}{\int_{0}^{t_{c}} \dot{W}_{c} d t+\int_{0}^{t_{r}} \dot{W}_{r} d t}
$$

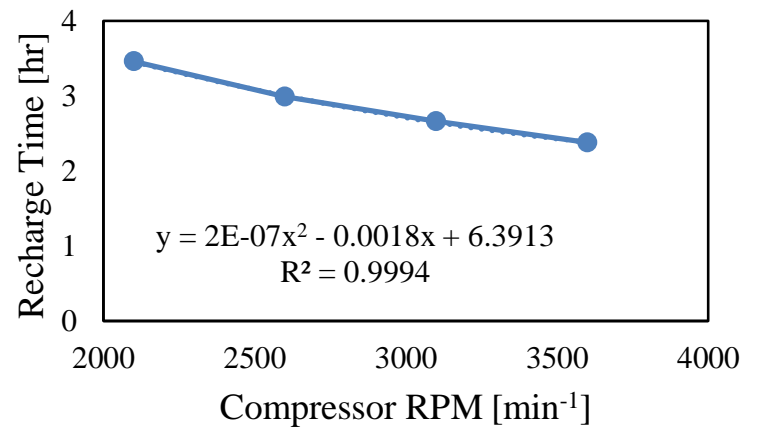

Figure 11. Recharge Time with Heat Pump Operation.

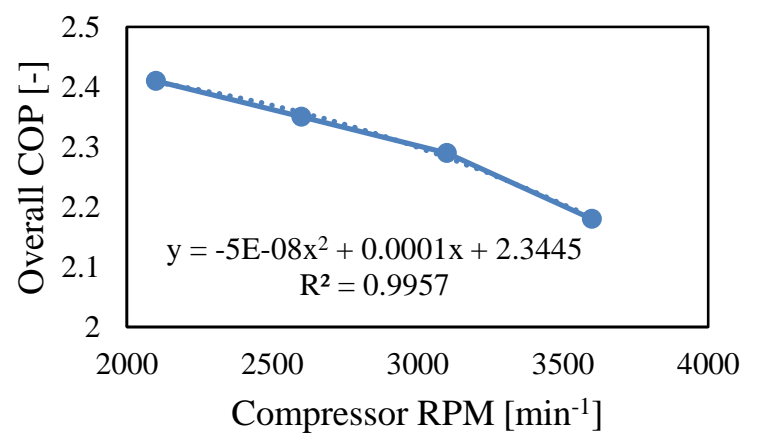

Figure 12. System COP with Heat Pump Operation.

Figure 10 illustrates the relationship between compressor RPM and RoCo charge time. As the compressor RPM increases from 2100 to 3600 , the vapor compression cycle capacity increases which leads to a one-hour reduction in recharge time. By examining the fitted equation, one can conclude that the relationship is not linear. This can be explained by the fact that although the refrigerant mass flow rate increases linearly with RPM, the increase of capacity is still restricted by the air sink. The higher RPM makes the heat exchangers undersized, and therefore, the slope of the curve in Figure 11 becomes smaller as the RPM increases.

Figure 12 demonstrates the relationship between compressor RPM and system COP. The COP tells the system efficiency under various compressor RPM cases. As previously explained, the higher RPM makes the heat exchangers undersized and therefore system less efficient. The reduction in COP worsens as the compressor rotates faster which can be spotted by the increased slope of the curve. 
The recharge period for the case with 3600 RPM is $55 \%$ lesser than that from thermosiphon, which is a significant improvement. Increase in RPM from 2100 to 3600 results in increased energy consumption of only 30 Wh. So, running the recharge at high RPM is definitely beneficial. The increase in energy consumption of RoCo will be in the order of a few hundred Wh, which may be easily offset from the savings from temperature set point elevation of building where energy consumption is in the order of thousand Wh. The model will be validated with experiment data in future to see how closely it predicts the heat pump cycle.

\section{CONCLUSIONS}

A physically based model of the graphite enhanced PCM is developed and then used in a system simulation for a reversible heat pump based recharge operation to investigate its potential benefits. The compressor RPM is varied to understand the heat pump operation at different operation conditions. Empirical correlations are generated to enable evaluation of heat pump performance based on simulation. The recharge period from heat pump operation is observed to be $55 \%$ lesser than that from thermosiphon. Heat pump recharge shows promise and needs experimental investigation.

\section{Acknowledgements}

This research was supported by the Advanced Research Projects Agency - Energy (ARPA-E) under Award DEAR0000530 and Center for Environmental Energy Engineering (CEEE). The authors acknowledge the support of the team members of the Roving Comforter Project.

\section{References}

Blasius, H. (1913) 'Das aehnlichkeitsgesetz bei reibungsvorgängen in flüssigkeiten', in Mitteilungen über Forschungsarbeiten auf dem Gebiete des Ingenieurwesens. Springer, pp. 1-41.

Cao, Y. and Faghri, A. (1991) 'Performance characteristics of a thermal energy storage module: a transient PCM / forced convection conjugate analysis', International Journal of Heat and Mass Transfer, 34, pp. 93-101.

Churchill, S. W. and Chu, H. H. S. (1975) 'Correlating equations for laminar and turbulent free convection from a vertical plate', International Journal of Heat and Mass Transfer. Elsevier, 18(11), pp. 1323-1329.

Dermont, P., Limperich, D., Windahl, J., Prolss, K., Kubler, C., (2016) 'Advances of Zero Flow Simulation of Air Conditioning Systems using Modelica', in The First Japanese Modelica Conferences, May 23-24, Tokyo, Japan. Linköping University Electronic Press, pp. 139144.

Dhumane, R., Ling, J., Aute, V., Radermacher, R., (2017)
'Portable personal conditioning systems: Transient modeling and system analysis', Applied Energy. Elsevier, 208, pp. 390-401. doi: 10.1016/j.apenergy.2017.10.023.

Dhumane, R., Mallow, A., Qiao, Y., Gluesenkamp, K.R., Graham, S., Ling, J., Radermacher, R., (2018)

'Enhancing the thermosiphon-driven discharge of a latent heat thermal storage system used in a personal cooling device', International Journal of Refrigeration. Elsevier, 88, pp. 599-613.

Dhumane, R., Qiao, Y., Ling, J., Muehlbauer, J., Aute, V., Hwang, Y., Radermacher, R., (2019) 'Improving System Performance of a Personal Conditioning System integrated with Thermal Storage', Applied Thermal Engineering. Elsevier, 147(25 January 2019), pp. 40-51.

Dittus, F. W. and Boelter, L. M. K. (1985) 'Heat transfer in automobile radiators of the tubular type', International Communications in Heat and Mass Transfer, 12(1), pp. 3-22.

Franke, R., Casella, R., Otter, M., Sielemann, M., Elmquvist, H., Mattson, S.E., Olsson, H., (2009) 'Stream connectors-an extension of Modelica for device-oriented modeling of convective transport phenomena', in Proceedings of the 7th International Modelica Conference; Como; Italy; 20-22 September 2009. Linköping University Electronic Press, pp. 108-121.

Heidarinejad, M., Dalgo, D.A., Mattise, N.W., Srebric, J., (2018) 'Personalized cooling as an energy efficiency technology for city energy footprint reduction', Journal of Cleaner Production. Elsevier, 171, pp. 491-505.

Hoyt, T., Arens, E. and Zhang, H. (2015) 'Extending air temperature setpoints: Simulated energy savings and design considerations for new and retrofit buildings', Building and Environment, 88, pp. 89-96. doi:

10.1016/j.buildenv.2014.09.010.

Kim, J., Schiavon, S. and Brager, G. (2018) 'Personal comfort models-A new paradigm in thermal comfort for occupant-centric environmental control', Building and Environment. Elsevier, 132, pp. 114-124.

Müller-Steinhagen, H. and Heck, K. (1986) 'A simple friction pressure drop correlation for two-phase flow in pipes', Chemical Engineering and Processing: Process Intensification. Elsevier, 20(6), pp. 297-308.

Qiao, H., Xu, X., Aute, V., and Radermacher, R. (2012) Modelica based transient modeling of a flash tank vapor injection system and experimental validation. the $14^{\text {th }}$ International Refrigeration and Air Conditioning Conferenc. West Lafayette, IN.

Qiao, H. (2014) Transient Modeling of Two Stage and Variable Refrigerant Flow Vapor Compression Systems with Frosting and Defrosting. Ph.D. Dissertation, University of Maryland, College Park

Qiao, Y., Mallow, A., Muehlbauer, J., Hwang, Y., Ling, J., Aute, V., Radermacher, R., Gluesenkamp, K.R., (2018) 'Experimental Study on Portable Air-Conditioning System with Enhanced PCM Condenser', in 17th International Refrigeration and Air Conditioning Conferenc. West Lafayette, IN. 
Shah, M. M. (1982) 'Chart correlation for saturated boiling heat transfer: equations and further study', ASHRAE Trans.;(United States), 88(CONF-820112-).

Shah, M. M. (2016) 'Comprehensive correlations for heat transfer during condensation in conventional and mini/micro channels in all orientations', International journal of refrigeration, 67, pp. 22-41. doi:

10.1016/j.ijrefrig.2016.03.014.

Wang, C.-C. and Chi, K.-Y. (2000) 'Heat transfer and friction characteristics of plain fin-and-tube heat exchangers, part I: new experimental data', International Journal of heat and mass transfer, 43(15), pp. 26812691. doi: 10.1016/s0017-9310(99)00332-4.

Zhang, H., Arens, E. and Zhai, Y. (2015) 'A review of the corrective power of personal comfort systems in nonneutral ambient environments', Building and Environment, 91, pp. 15-41. doi: 10.1016/j.buildenv.2015.03.013. 
